\title{
A System for Determination of Areas Hazardous for Blind People Using Wave-vibration Markers - Final Conclusions and Technical Application
}

\author{
J. WiCIAK*, B. Borkowski AND D. CZOPEK \\ AGH - University of Science and Technology, Faculty of Mechanical Engineering and Robotics \\ Department of Mechanics and Vibroacoustics, al. A. Mickiewicza 30, 30-059 Krakow, Poland
}

\begin{abstract}
The paper constitutes a summary of the work carried out under the research project entitled The development of the method for marking and identification of the spots dangerous and of special importance for vision impaired persons in the big city with use of the wave-vibration markers. This article discusses key researches conducted during the project, including review of influence of environmental sounds on orientation and mobility of blind and partially sighted people, results of vibration perception threshold measurement taken at the wrist of both hands, measurements of paraseismic vibrations and results of researches on annoyance, recognizability and easiness to learn of selected signals.
\end{abstract}

DOI: $10.12693 /$ APhysPolA.123.1101

PACS: 43.66.Wv, 43.66.Yw, 46.40.-f, 07.10.-h

\section{Introduction}

Universal design thinking has become widely recognized and applied in many countries around the world. It is defined as such design of products and environment that can be usable by all people, to the greatest extent possible, without the need for adaptation or specialized design. One of the primary aims of the universal design strategy is to promote equality for and ensure the full participation in society of individuals with reduced functionality, by removing existing disabling barriers and preventing new ones from emerging. This idea should not be realized by specially-targeted solutions but by solutions which are designed to anticipate the needs of all users [1]. In Poland, according to the National Census conducted in 2011, there is at least 4697.5 thousand people with disabilities which make $12.2 \%$ of Polish population $[2,3]$.

The mobility of the blind and visually impaired significantly depends on the ability of spatial orientation skills and mastering the techniques of movement [4]. Since 2009 there is a research project being carried out at AGH - University of Science and Technology which aims at developing a method of using wave-vibration tags in marking dangerous and significant places for the blind in urban areas

Currently a prototype system for marking and identification of the spots dangerous and of special importance for vision impaired persons in the big city with the use of the wave-vibration markers was developed $[5,6]$. Designed system comprises three modules:

- BRACELETS: using vibrations i.e. the sense of touch

*corresponding author; e-mail: wiciak@agh.edu.pl
- ANTENNA: transmitting and receiving system that records the appearance of a blind person in the area hazardous or important for the blind and then sends the information to the controller.

- CONTROLLER: receives information from the antenna, analyzes it and transmits appropriate signals to the bracelet.

In the paper, the scientific milestones of the project are presented, including the review of the effect of environmental sounds on orientation and mobility of blind and partially sighted people, results of vibration perception threshold measurement taken at the wrist of both hands, measurements of paraseismic vibrations and results of researches on annoyance, recognizability and easiness to learn of selected signals.

\section{Methodology of research}

\subsection{Choice of the spots dangerous and of special importance - survey}

A total of 244 questionnaires were collected and used for the analysis. 77 blind people (31.6\% of respondents) and 167 partially sighted people ( $68.4 \%$ of respondents), 96 women (39.3\% of respondents) and 148 men (60.7\% of respondents) participated in the survey. Most of the respondents were between 13 and 30 years old $(81 \%$ of respondents) what indicates their level of education. A detailed description of the respondents is shown in Figure 1. The majority of the participants in the survey declared themselves as users of collective transportation. Only $3 \%$ of the respondents stated that they do not move around the city by themselves. Responses of these participants were excluded from the analysis.

At first, descriptive statistics were used to describe the basic features of the data in a study. All or part of the 


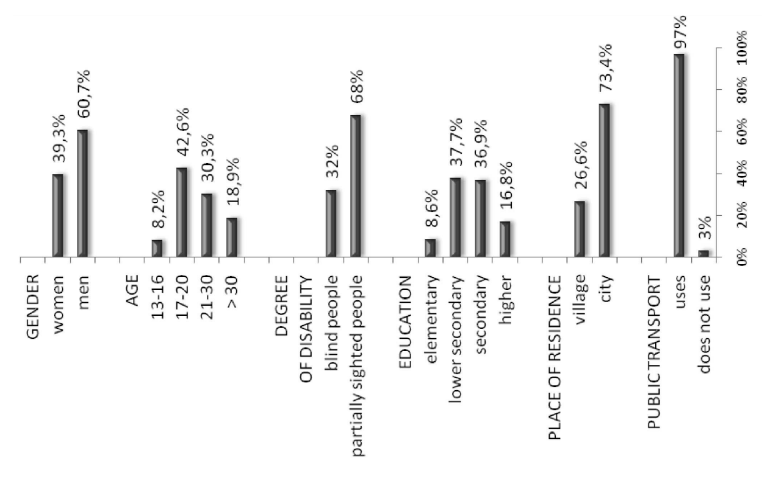

Fig. 1. Characteristic of respondents.

data chosen according to the criterion of the degree of disability were used to analysis. Descriptive statistics provide simple summaries about differences in the opinions of people who are blind and partially sighted. The results indicates that the degree of disability of the respondents is instrumental in spatial orientation and perception of sounds in an urban environment. This hypothesis was tested. Therefore, the chi-square compatibility test was used. For the calculations option $2 \times 2$ tables from set of nonparametric statistics of Statistica 8.0 made by StatSoft was used. For significance level $\alpha=0.01$ and with one degree of freedom critical value of $\chi$-square statistics is $6.63490[7,8]$. Results are shown in Table I.

Answer to the question which sites should be marked hid in the answer to open questions. Analysis of these data was complicated due to the huge amount of different information. An attempt was made to classify data in groups of related events and locations.

\subsection{Paraseismic vibrations}

The measurement system used during the study consisted of SVAN 958 sound and vibration analyzer and two seismic vibration sensors (PCB 393B05 and DYTRAN 3191A1) During the measurements the sensors were mounted on special steel stands with mass at least 10 times greater that sensor mass, mounted to the sensor that ensured transiting the signal in all measurement range. Stands had also stable contact with the surface and it was possible to level a stand (which was achieved by 3 adjustable feet). Because of the sensors characteristics and specifics of the task measurement range was chosen as $0.8-450 \mathrm{~Hz}[9,10]$.

The measurements of paraseismic vibrations were performer for following cases [11]:

- vibrations of the pavement

- vibrations of the island between 2 roadways

- vibrations of the bus stop

- vibrations of the tram stop

- vibrations of the underground tram stop
- vibrations of the footbridge above the road

- vibrations of the pedestrian crossing

\subsection{Choice of frequency and amplitude of vibration signals emitted by the bracelet - vibration perception thresholds}

One of the elements of the system for identification of hazardous and important places is the vibration transducer worn by a blind person on the wrist. In the process of sensing an external stimulus, four mechanoreceptors: Pacinian corpuscles, Meissner's corpuscles, Merkel's discs, and Ruffini endings are taking part. Each sensory receptor is sensitive to a distinct type and pattern of energy, and responds to a selective amount of stimulus for activation. Irrespective of the type of stimulus energy experienced by a sensory receptor, the stimulus is converted to an electrical signal that is then conducted to the central nervous system. The specific response of mechanoreceptors is determined by the following features: sensitivity to the specific type and frequency of mechanical stimulus, the size of the field excitation of the receptor, and the speed of adaptation of the receptor to the stimulus.

For this reason it was necessary to determine vibration perception thresholds at the wrist. The measurements were performed in 15 of blind and visually impaired people and in the reference group of 15 sighted people. The measurements of vibrotactile perception thresholds were taken using a test set consisting of P8 Pallesthesiometer (EMSON-MAT, Poland) and a computer. The study relied on measurement of sinusoidal vibration at a given frequency by Békésy method [12] according to ISO standard [13] The measuring points, i.e. areas where a vibrating probe tip had contact with the skin are shown in Fig 2. The study was conducted with a $5 \mathrm{~mm}$ diameter probe, the stimuli force was $0.1 \mathrm{~N}$ and the frequencies were $4,25,32,64,125,250,400$, and $500 \mathrm{~Hz}$.

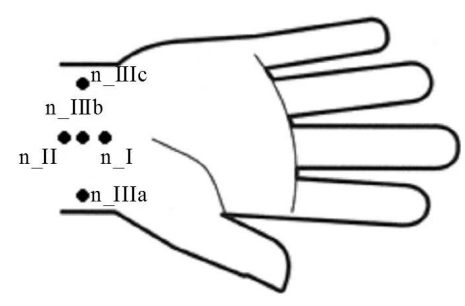

Fig. 2. Layout of measurement points.

\subsection{Choice of vibration signals emitted by the bracelet}

Based on the survey, 6 spots dangerous and of special importance for blind and partially sighted people in the big city were selected. For each spot a few different sequence of vibrations were composed. To do this, measurement of vibration perception threshold and measurements of paraseismic vibrations were used. After preliminary tests 14 vibration signals were chosen for further 
study. 18 blind and partially sighted people participated in the experiment.

At the beginning, an examined person was acquainted with test procedure and informed about possibility to make a break whenever it would be necessary. The whole experiment was carried out in 2-30-minutes long sessions. Perception of signals was evaluated using short 5-point ICBEN scale [14, 15].

During the first part of the test, 14 signals were presented singly to evaluate their annoyance and ease to learn and memorize Each of the 14 signals was presented 3 times. The signals were presented in random order. The subjects were asked the following question: "What number from one to five reflects in the best way how much you are annoyed by signal? If you are not annoyed at all, choose one; if you are extremely annoyed, choose five; if you are somewhere in between, choose a number between one and five." In the case of evaluation memorable of signals, the question was analogous: "What number from one to five reflects in the best way how easy to learn and memorize is the signal? If it is very easy, choose one; if it is extremely difficult, choose five; if it is somewhere in between, choose a number between one and five."

In the second part of the test signals were connected into 91 pairs These pairs were presented to evaluate their recognizability. Each of the 91 pairs was presented once. Pairs were presented in random order. The subjects were asked the following question: "What number from one to five reflects in the best way how much the signals are similar to each other? If they are completely different, choose one; if they are identical, choose five; if they are somewhere in between, choose a number between one and five."

\section{Results}

According to survey dangerous and of special importance spots were selected as follows:

- staircases with differentiation of direction,

- rail platform,

- tram platform

- pedestrian crossing (with and without lights, with sound/ speaker system),

- temporary obstacles: excavations, road works, temporary bridges,

- in public buildings.

The developed system can also cooperate with the tourist information system.

The survey also provided knowledge about the visually impaired community, e.g. on the effect of environmental sounds and atmospheric phenomena on orientation and mobility of blind and partially sighted people (Figure 3). Traffic noise and noise from construction machinery significantly hinder the orientation of blind people. The most important sound is the sound emitted by pedestrian traffic light. In Table I. results of tests of hypothesis that the degree of disability of the respondents is instrumental in spatial orientation and perception of sounds in an urban environment are shown.

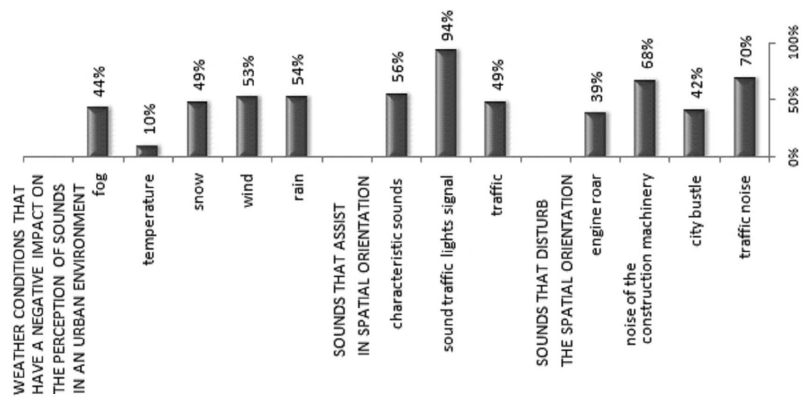

Fig. 3. Sounds that assist and disturb the spatial orientation and negative impact of weather conditions on the perception of sounds in an urban environment.

TABLE I

Input data and results of chi-square test.

\begin{tabular}{l|c|c|c|c|c|c|c}
\hline \hline & $\begin{array}{c}\text { Blind } \\
\text { people }\end{array}$ & $\begin{array}{c}\text { Partially } \\
\text { sighted }\end{array}$ & \multirow{2}{*}{$\chi^{2}$} & $p$-value & Result \\
\cline { 2 - 5 } yes & no & yes & no & & & \\
\hline \multicolumn{7}{c}{ sounds disturbing spatial orientation } \\
\hline traffic noise & 61 & 16 & 103 & 53 & 431 & 0.380 & $H_{a}$ \\
\hline city bustle & 42 & 35 & 55 & 101 & 789 & 0.0050 & rejection $H_{0}$ \\
\hline $\begin{array}{l}\text { noise of the construction } \\
\text { machinery }\end{array} 65$ & 12 & 94 & 62 & 1388 & 0.002 & rejection $H_{0}$ \\
\hline engine roar & 36 & 41 & 54 & 102 & 320 & 0.735 & $H_{a}$ \\
\hline \multicolumn{7}{|c|}{ sounds helping in spatial orientation } \\
\hline traffic & 58 & 19 & 59 & 101 & 35.75 & 0.0000 & rejection $H_{0}$ \\
\hline sound of traffic lights \\
signal & 74 & 3 & 148 & 12 & 1.14 & 0.2859 & $H_{a}$ \\
\hline $\begin{array}{l}\text { sounds characteristic of a particular area }(\text { churches, } \\
\text { opening the door, the sound of air-conditioning on the }\end{array}$ \\
buildings & 55 & 22 & 78 & 82 & 10.86 & 0.0010 & rejection $H_{0}$ \\
\hline \multicolumn{7}{|c|}{ weather conditions } \\
\hline rain & 50 & 26 & 77 & 81 & 6.01 & 0.0142 & $H_{a}$ \\
\hline wind & 50 & 26 & 74 & 84 & 7.40 & 0.0065 & rejection $H_{0}$ \\
\hline snow & 48 & 28 & 67 & 91 & 8.84 & 0.0029 & rejection $H_{0}$ \\
\hline temperature & 9 & 67 & 15 & 143 & 0.31 & 0.5792 & $H_{a}$ \\
\hline
\end{tabular}

\section{Blind people}

- City bustle and noise of the construction machinery are considered sounds that disturb spatial orientation in blind people.

- Traffic and sounds characteristic for a particular area (church bells, opening the door, the sound of air-conditioning in the buildings) are considered sounds that help blind people in spatial orientation. 
- The effect of wind and snow on reception of sounds from urban environment is more important for blind people.

\section{Partially sighted people}

- The effect of fog on reception of sounds from urban environment is more important for partially sighted people.

\section{Both}

- Traffic noise and engine roar are considered sounds that disturb the spatial orientation in both the blind people and the partially sighted people.

- Sound traffic lights signal is considered as a sound that helps in spatial orientation both the blind people and the partially sighted people.

- The effect of rain and temperature on reception of sounds from urban environment is equally important for the blind and partially sighted people. In fact, the effect of rain is more significant than this of ambient temperature.

Results of chi-square test shown that people with different degree of disability perceived sound in different way. In research on soundscape sounds are divided into three categories "keynote sounds", "signals" and "soundmarks" [16]. This division based on evaluation whether the sounds are perceived consciously or unconsciously. Results shows that sounds that blind people perceive consciously, are background sounds for partially sighted people.

Figure 4 shows vibration detection threshold on the wrist depending on frequency for the probe with a diameter of $5 \mathrm{~mm}$ for both groups of respondents, averaged from following measurement points: $n_{-} I, n_{-} I, n_{-} I I I a$, $n I I I b$ and $n$ IIIC. Vertical bars represent the 0.95 confidence intervals.

Measurements of paraseismic vibrations were analyzed in accordance with the standard concerning the effect of vibrations on human organism. First 1/3-octave spectral analysis in frequency range from $1 \mathrm{~Hz}$ to $400 \mathrm{~Hz}$ were made. Then for each case characteristic bands were found. Finally those bands were compared with the results of similar study conducted in Poznań (Table II)

\section{Conclusions}

The analysis of the survey and other research leads to the following conclusions:

- Information provided by hearing is very important in spatial orientation both for the blind and the partially sighted people.

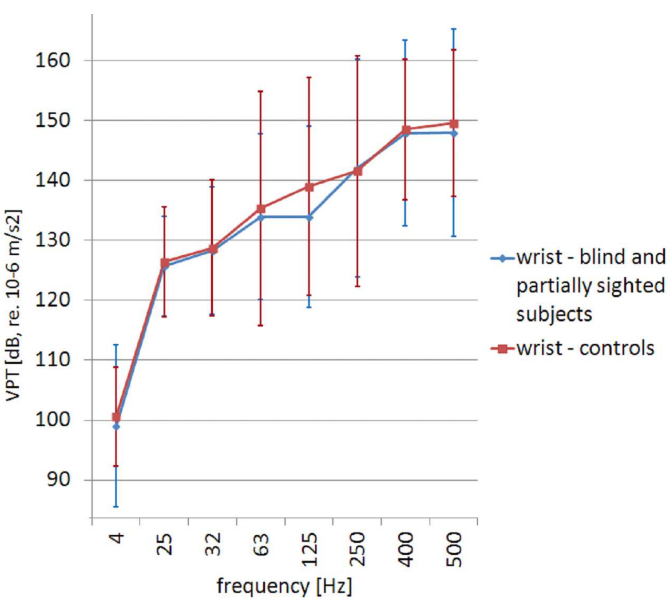

Fig. 4. Vibration detection threshold on the wrist depending on frequency for the probe with a diameter of 5 $\mathrm{mm}$ for both groups of respondents, average value from 5 points.

TABLE II

Comparison of characteristic frequency bands measured in Kraków and Poznań [11, 17]

\begin{tabular}{l|c|c}
\hline \hline \multirow{2}{*}{$\begin{array}{l}\text { Measurement } \\
\text { point }\end{array}$} & Characteristic frequency band [Hz] \\
\cline { 2 - 3 } pavement & $16-80$ & Kraków \\
\hline $\begin{array}{l}\text { island } \\
\text { between }\end{array}$ & $25-63$ & $16-5-40,125-400$ \\
\hline roadways & & $10-16,100-315$ \\
\hline bus stop & $4-16,200-400$ & $16-400$ \\
\hline tram stop & $16-400$ & $63-400$ \\
\hline $\begin{array}{l}\text { underground } \\
\text { tram stop }\end{array}$ & - & - \\
\hline $\begin{array}{l}\text { railway } \\
\text { station }\end{array}$ & $16-50$ & $25-80$ \\
\hline $\begin{array}{l}\text { pedestrian } \\
\text { crossing }\end{array}$ & $25-63$ & $1.25-250$ \\
\hline $\begin{array}{l}\text { footbridge } \\
\text { above road }\end{array}$ & $8-630$ & \\
\hline $\begin{array}{l}\text { coach station } \\
\text { poun }\end{array}$ & $8-31.5,63-315$ &
\end{tabular}

- Sound traffic lights signal is considered as a sound that helps in spatial orientation both the blind people and the partially sighted people. It is foreground sound ("signals") which is treat as warning signs and is listened consciously by both group of respondents.

- Reception of other ambient noises depends on the degree of disability of a person moving around the city. Blind people draw attention to the acoustic stimuli significantly more than partially sighted people. Blind people while moving use consciously almost every heart sound. Partially sighted people draw more attention to information provided by the remnants of sight. 
- Often, the same acoustic phenomenon both supports and disrupts the spatial orientation. Blind and partially sighted people agreed that traffic noise disturb the spatial orientation. But almost the same number of the blind claimed that traffic noise help the spatial orientation while among partially sighted much less (half of those who pointed that traffic noise disturb spatial orientation).

- Opinion on how much the weather interferes with the reception of ambient sound depends on the degree of disability of the respondent.

- In the cities, the number of sound signals is so big that often the information that they carry becomes unreadable.

- Signals used in the system to aid spatial orientation of blind and visually impaired people should avoid some frequencies between $10 \mathrm{~Hz}$ and $400 \mathrm{~Hz}$ because of the possibility of its signals being mixed up with signals coming from the environment, or should use acoustic signal as well as vibrations

- In measurements of vibrotactile perception threshold no statistically significant difference between the results of a group of blind and partially sighted people and the results of the reference group is observed

- The acceleration level of the developed device should exceed the detection threshold by at least $10 \mathrm{~dB}[18]$

Solutions supporting spatial orientation based on sound information increase the number of acoustic stimuli. In addition, they do not work well when there is excessive noise. The idea of creating a system based on vibration signals and the sense of touch is well-founded, because it does not interfere with the reception of the natural sound environment. Furthermore, such a system can be used by the deafblind people.

\section{Acknowledgments}

We would like to thank the teachers of spatial orientation from the Institute for the Blind and Partially Sighted in Cracow for their help with preparing and conducting the survey.

This study is a part of the NR17001706 research project supported by the National Center for Research and Development (NCBR), Poland.

\section{References}

[1] Universal design. Clarification of the concept. The Norwegian Ministry of the Environment, 2007.

[2] L. Nowak, National Census in 2011, Central Statistical Office, Statistical Publishing Establishment Warsaw 2012.

[3] N. Koehne, B. Lednicki, M. Piekarzewska, R. Wieczorkowski, A. Zajenkowska-Kozłowska, The health status of the Polish population in 2009, Central Statistical Office, Statistical Publishing Establishment, Warsaw 2011.

[4] M. Wysocki, Designing Environments for Blind People. Nonvisual Perception of Space, Gdansk University of Technology Publishing, Gdansk 2010.

[5] J. Wiciak, B. Borkowski, Acta Phys. Pol. A 119, 921 (2011).

[6] J. Wiciak, B. Borkowski, I. Czajka, Acta Phys. Pol. A 121, A-24 (2012).

[7] R.L. Scheaffer, J.T. McClave, Probability and statistics for engineers, PWS-KENT Publishing Company, Boston 1986.

[8] A. Sokołowski, in: Statistica in research and teaching of statistics, StatSoft, Kraków 2010, p. 25.

[9] Z. Engel, Environmental protection against vibration and noise, Scientific Publishing PWN, Warsaw 2001.

[10] K. McConnell, P. Varoto, Vibration testing. Theory and Practice, John Wiley, Hoboken (NJ) 2008.

[11] J. Wiciak, R. Trojanowski, Polish J. Environm. Stud. 21, 440 (2012).

[12] M.S. Gandhi, R. Sesek, R. Tuckett, J. Hand Ther. 24, 240 (2011).

[13] Polish Standard PN-ISO, 13091-1:2001.

[14] J.M. Fields, R.G. De Jong, T. Gjestland, I.H. Flindell, R.F.S. Job, S. Kurra, P. Lercher, M. Vallet,T. Yano, R. Guski, U. Felscher-Suchr, R. Schumer, J. Sound Vibr. 242, 641 (2001).

[15] A. Preis, B. Griefhahn, T. Gjestland, Report to partners: Guidelines concerning priorities of noise abatement, retrieved on 25.01.2013.

[16] J. Herssens, L. Roelants, M. Rychtáriková, A. Heylighen, Listening in the Absence of Sight: The Sound of Inclusive Environments, Proceedings of Include 2011.

[17] B. Czechyra, E. Skrodzka, G. Szymański, F. Tomaszewski, J. Wiciak, Polish J. Environm. Stud. 20, 45 (2011).

[18] E. Bogusz, G. Mrozik E. Skrodzka, Acta Phys. Pol. A 121, A-19 (2012). 